\title{
Medium and Large Mammalian Diversity of Loka Abaya National Park, Southern Ethiopia
}

\author{
Girma Mengesha ${ }^{1}$ \\ ${ }^{1}$ Wondo Genet College of Forestry and Natural Resources
}

May 5, 2020

\begin{abstract}
We evaluated the richness, diversity and composition of medium and large mammalian community in the Loka Abaya National Park (LANP), southern Ethiopia, and how these parametrs differ among four habitat types: wooded grassland, riverine forest, hilly scrubland and wetland) and between seasons. We recorded total of 2,573 individual animals of 28 medium and large mammal species in the park. This included three globally threatened species: the endangered African wild-dog (Lycaon pictus) and the 'vulnerable' Leopard (Penthra pardus) and Hippopotamus (Hippopothamus amphibus). Season had little effect on species richness, diversity and composition both across and within habitat types. However, species richness across season was significantly different among the four habitat types, in declining order of: wooded grassland $>$ riverine forest $>$ hilly scrubland $>$ wetland. The strongest similarity in species composition, both across and within seasons, was found between wooded grassland and riverine forest. In terms of relative abundance, mammalia assemblage of the wooded grassland and wetland habitats had more evenly distributed number of species with different relative abundance categories. Overall, Papio anubis, Chlorocebus aethiops and Tragelephus strepsiceros were the three most abundant species across habitat types. In conclusion, findings of our study reveal that LANP plays an important role in Ethiopia's mammal conservation. Our findings will serve as a base-line information for managers of the park to make effective conservation decisions and as a baseline for researchers wishing to conduct related ecological studies.
\end{abstract}

\section{Hosted file}

Guta Diriba et al for submission to Ecology and Evolution, main document.doc available at https://authorea.com/users/316931/articles/447043-medium-and-large-mammalian-diversityof-loka-abaya-national-park-southern-ethiopia

\section{Hosted file}

Figures Guta et al for submission.docx available at https://authorea.com/users/316931/ articles/447043-medium-and-large-mammalian-diversity-of-loka-abaya-national-parksouthern-ethiopia 